\title{
The effect of methacholine-induced acute airway narrowing on lung sounds in normal and asthmatic subjects
}

\author{
H.J.W. Schreur*, J. Vanderschoot**, A.H. Zwinderman\#, J.H. Dijkman*, P.J. Sterk*
}

The effect of methacholine-induced acute airway narrowing on lung sounds in normal and asthmatic subjects. H.J.W. Schreur, J. Vanderschoot, A.H. Zwinderman, J.H. Dijkman, P.J. Sterk. COERS Journals Ltd 1995.

ABSTRACT: The association between lung sound alterations and airways obstruction has long been recognized in clinical practice, but the precise pathophysiological mechanisms of this relationship have not been determined.

Therefore, we examined the changes in lung sounds at well-defined levels of methacholine-induced airway narrowing in eight normal and nine asthmatic subjects with normal baseline lung function. All subjects underwent phonopneumography at baseline condition and at $\geq \mathbf{2 0 \%}$ fall in forced expiratory volume in one second $\left(\mathrm{FEV}_{1}\right)$, and in asthmatic subjects also at $\geq \mathbf{4 0 \%}$ fall in $\mathrm{FEV}_{1}$. Lung sounds were recorded at three locations on the chest wall during standardized quiet breathing, and during maximal forced breathing. Airflow-dependent power spectra were computed using fast Fourier transform. For each spectrum, we determined the intensity and frequency content of lung sounds, together with the extent of wheezing. The results were analysed using analysis of variance (ANOVA).

During acute airway narrowing, the intensity and frequency content of the recorded sounds, as well as the extent of wheezing, were higher than at baseline in both groups of subjects. At similar levels of obstruction, both the pitch and the change in sound intensity with airflow were higher in asthmatics than in normal subjects. Wheezing, being nondiscriminative between the subject groups at baseline, was more prominent in asthmatics than in normal subjects at $20 \%$ fall in $\mathrm{FEV}_{1}$.

We conclude that, at given levels of acute airway narrowing, lung sounds differ between asthmatics and normal subjects. This suggests that airflow-standardized phonopneumography is a sensitive method for detecting abnormalities in airway dynamics in asthma. Our results favour the use of quiet, well-controlled breathing during auscultation.

Eur Respir J., 1995, 8, 257-265.
*Dept of Pulmonology, University Hospital Leiden, The Netherlands. Depts of ** Medical Informatics, and "Medical Statistics, Leiden University, The Netherlands.

Correspondence: H.J.W. Schreur Lung Function Laboratory, C2-P University Hospital Leiden P.O. Box 9600 NL-2300 RC Leiden The Netherlands

Keywords: Lung sounds methacholine challenge pulmonary acoustics wheezing

Received: March 291994

Accepted after revision November 161994

This study was supported by grant 90.34 of The Netherlands Asthma Foundation.
Lung sounds are generally considered to provide clinically relevant information in asthma, even though this has not been substantiated by quantitative analysis of objective measurements. Asthma is a chronic disease with variable airways obstruction, in which the airways are characterized by inflammatory changes resulting in mucosal swelling of the airway wall, thickening of the basement membrane, smooth muscle hypertrophy or hyperplasia, and excessive mucus production [1]. These inflammatory changes are present even in clinically stable asthmatics without any current symptoms and with lung function within the normal range [2]. Using computerized phonopneumography, we have previously observed that lung sound intensity is lower and pitch is higher in symptom-free, mildly asthmatic subjects with lung function within the normal range as compared with healthy controls [3]. This suggests that the generation and/or transmission of lung sounds is altered as a result of the morphological changes of the airways in asthma, even when there are no discernable symptoms or spirometric changes.
Lung sounds can be divided into normal and adventitious sounds, e.g. wheezes. The characteristics of normal lung sounds as well as wheezes are influenced by airflow velocity and local properties of the airways [4, 5]. Normal lung sounds appear to be primarily generated by the complex turbulence within the large and medium sized airways $[4,6]$. The differences in intensity and pitch of lung sounds at baseline between asthmatic and normal subjects could be due to swelling of the airway wall in patients with asthma [3], which may lead to localized reduction of the airway lumen. Any resulting increase in local airflow velocity $\left(\mathrm{m} \cdot \mathrm{s}^{-1}\right)$ at given flows at the mouth $\left(l \cdot \mathrm{s}^{-1}\right)$ will enhance turbulence, thus increasing the intensity and frequency content of the sounds generated [4]. On the other hand, it is likely that the transmission of lung sounds to the chest is reduced in asthma by increased mismatches of the acoustical impedance across thickened airway walls [7].

One way of distinguishing the effects of the generation and transmission of lung sounds in asthma might be the induction of acute airway narrowing by a 
bronchoconstrictive stimulus. Smooth muscle contraction will increase the generation of normal lung sounds due to increased local airflow velocity. However, during smooth muscle contraction there will be an increase in airway wall thickness [8,9], possibly combined with a decrease in parenchymal density $[10,11]$. Therefore, the possibility that acute airway narrowing reduces sound transmission to the chest wall to some extent cannot be excluded [7].

Wheezing is induced by quick oscillations of intraluminal gas and collapsible airway walls when airflow has reached critical velocity (Bernoulli effect) $[4,5]$. The occurrence of wheezing is dependent on airflow velocity and on mechanical and geometrical properties of the airways at the site of the flow-limiting segment [5]. Flutter theory predicts that wheezing during expiratory flow-limitation will occur at lower airflow velocities when airway diameter is decreased $[4,5]$. At baseline, the airways are probably too wide to show differences in the extent of wheezing between asthmatic and normal subjects [3]. However, during bronchoconstriction intraluminal airflow velocity at given flows at the mouth will be higher, so that critical velocity will be reached at relatively low airflows. This will cause flow-limitation and wheezing to occur at lower airflows at the mouth. As the relative change in intraluminal airway diameter during smooth muscle contraction will not be different between asthmatics and normal subjects at a given change in lung function, we anticipated a similar increase in the extent of wheezing in both subject groups [5].

In the present study, we investigated the effect of acute, smooth muscle-induced airway narrowing on lung sounds, recorded by flow- and volume-standardized phonopneumography in subjects with and without evidence of preexisting airways inflammation. To that end, we compared lung sound intensity, frequency content, and extent of wheezing before and after inhalation of methacholine between normal and mildly asthmatic subjects.

\section{Subjects and methods}

\section{Subjects}

Nine atopic men with mild asthma (mean age $25 \mathrm{yrs}$; range 19-28 yrs) and eight healthy male controls (mean age 22 yrs; range 19-24 yrs), of whom baseline characteristics have been reported previously [3], volunteered to participate in this study (table 1). All subjects were lifelong nonsmokers, and there was no history of respiratory tract infection within 4 weeks before the study. The asthmatics had a history of episodic chest tightness and wheezing, but they were clinically stable for at least 4 weeks prior to the study. They were treated by ondemand usage of inhaled short-acting $\beta_{2}$-adrenergic bronchodilators alone, that were withheld for at least $12 \mathrm{~h}$ before each study visit. Corticosteroids, theophylline, antihistamines, cromolyn sodium, or nedocromil sodium had not been used for at least 6 months prior to the study. All asthmatics had positive skin-prick tests (wheal $>3$ $\mathrm{mm}$ ) to one or more airborne allergens. Forced expira- tory volume in one second $\left(\mathrm{FEV}_{1}\right)$ without bronchodilator was within the normal range (mean $94 \%$ of predicted; range $77-119 \%$ pred) [12]. The asthmatics showed airway hyperresponsiveness to inhaled methacholine, as indicated by a lowered provocative concentration required to cause a $20 \%$ decrease in $\mathrm{FEV}_{1}\left(\mathrm{PC}_{20} \leq 4.0 \mathrm{mg} \cdot \mathrm{ml}^{-1}\right)$ [13], together with a maximal-response on the doseresponse curve to methacholine greater than $40 \%$ fall in $\mathrm{FEV}_{1}$.

The healthy controls had a negative history of lung disease, a normal physical examination, and did not use any relevant medication within 3 months before the study. $\mathrm{FEV}_{1}$ was within the normal range (mean $\mathrm{FEV}_{1} 109 \%$ pred; range $88-126 \%$ pred) [12], and they had normal airway responsiveness to methacholine (PC20 $\geq 25.0$ $\left.\mathrm{mg} \cdot \mathrm{ml}^{-1}\right)$ [13]. The maximal-response on the dose-response curve to methacholine was greater than $20 \%$ fall in $\mathrm{FEV}_{1}$. The study was approved by the Hospital Ethics Committee, and informed consent was obtained from all subjects.

\section{Design}

The study consisted of a screening day, and two study days with an interval of 2-3 days. On the screening day, the selection criteria were checked, and the subjects were familiarized with the recording procedures. On both study days, the subjects underwent identical procedures for determination of the repeatability. On each day, measurements of baseline $\mathrm{FEV}_{1}$ were followed by baseline phonopneumography (PPGBL). Subsequently, doubling doses of methacholine were inhaled until a $20 \%$ fall from baseline in $\mathrm{FEV}_{1}$ had been reached, followed by phonopneumography (PPG20\%). In the asthmatic subjects, the inhalation challenge was continued until a fall in $\mathrm{FEV}_{1}$ of $40 \%$ had been reached, followed by a third phonopneumographic recording (PPG40\%). They then inhaled $200 \mu \mathrm{g}$ salbutamol from a metered-dose inhaler to provide acute bronchodilation. The PPG recordings and the doseresponse curves to methacholine were recorded on both study days at the same time of day $\pm 30 \mathrm{~min}$ for each subject, and baseline $\mathrm{FEV}_{1}$ had to be within $5 \%$ between the days in each subject.

\section{Measurements}

Methacholine-inhalation tests were performed according to a standardized procedure [13]. Dose-response curves were obtained by having the subject inhale doubling concentrations from 0.12 to $512 \mathrm{mg} \cdot \mathrm{ml}^{-1}$ of methacholine (acetyl- $\beta$-methacholine chloride, Sigma Chemical Co., St. Louis, MO, USA) dissolved in normal saline. Methacholine solutions were stored at $4^{\circ} \mathrm{C}$ and nebulized at room temperature. The aerosols were generated using a DeVilbiss 646 nebulizer (DeVilbiss, Somerset, $\mathrm{Pa}$, USA) operated by oxygen (output $0.13 \mathrm{ml} \cdot \mathrm{min}^{-1}$ ), and were inhaled by tidal breathing for $2 \mathrm{~min}$ at $10 \mathrm{~min}$ intervals with the nose clipped. $\mathrm{FEV}_{1}$ at baseline was obtained from the highest value of two recordings, using the calibrated pneumotachograph (Morgan Plethysmograph, Rainham, Gillingham, UK) [12]. During the 
methacholine challenge, single measurements of $\mathrm{FEV}_{1}$ were made at 90 and $120 \mathrm{~s}$ after each dose. The tests were discontinued if $\mathrm{FEV}_{1}$ decreased by more than $20 \%$ from baseline in normals, and by more than $40 \%$ in asthmatics, or when a concentration of $512 \mathrm{mg} \cdot \mathrm{ml}^{-1} \mathrm{had}$ been administered.

Phonopneumography was carried out at baseline (PPGBL), and $5 \mathrm{~min}$ after the methacholine dose at which $20 \%$ or $40 \%$ fall in $\mathrm{FEV}_{1}$ from baseline (PPG20\% and PPG40\%, respectively) had been reached. Phonopneumography included simultaneous registrations of lung sounds in a soundproof room, and measurements of airflow and lung volume changes at the mouth by spirometry (Spiroflow; Morgan, Rainham, Gillingham, UK) according to a previously validated method [3]. The lung sound recordings were made during flow- and lung volume-standardized quiet breathing with flow rates up to $1.5 l \cdot \mathrm{s}^{-1}$, and lung volumes between TLC $-0.4 \times \mathrm{VC}+/-1 l$ for $30 \mathrm{~s}$ (TLC: total lung capacity, VC: vital capacity), and during maximum forced flow-volume manoeuvres for $15 \mathrm{~s}$. The subjects were seated in an upright position with their nose clipped. Soda lime was used to eliminate $\mathrm{CO}_{2}$ accumulation in the spirometer, and $300 \mathrm{ml} \cdot \mathrm{min}^{-1} \mathrm{O}_{2}$ was supplied to compensate for the $\mathrm{O}_{2}$ uptake.

The standardized quiet breathing manoeuvre started with a maximum inspiration towards TLC, used as a reference volume. The subjects then performed the quiet manoeuvres by tracking a prescribed loop on an oscilloscope screen (Hewlett-Packard HP1741A, Santa Clara, CA, USA) in front of the subject, displaying changes in airflow and lung volume [3]. The actual registration started $45 \mathrm{~s}$ after the initial maximum inhalation to enable the airways to recover from any deep breath effect on airway tone [14]. Recordings were accepted when the target flow and volume were not exceeded by more than $0.5 l \cdot \mathrm{s}^{-1}$ and $0.25 l$, respectively.

The registrations of the maximum forced respirations were made directly after the quiet manoeuvres. The occurrence of flow limitation during the quiet breathing manoeuvres was excluded by the comparison of flowvolume curves obtained from these manoeuvres with the flow-volume curves from the maximum forced manoeuvres for coincidence or overlapping. Inspection of the superimposed flow-volume curves of each individual subject showed a strong similarity between these curves. Exceptions to this were the transitions between expiration and inspiration in both manoeuvres, and segments with maximum airflow in the forced manoeuvres. To avoid deviations in the flow-volume curves from the target curves to influence the results of this study, we excluded spectra at airflows $<0.3 \mathrm{l} \cdot \mathrm{s}^{-1}$ during quiet breathing, $<0.6 l \cdot \mathrm{s}^{-1}$ during forced manoeuvres, and $>3.6$ and $>6.0 \mathrm{l} \cdot \mathrm{s}^{-1}$ in forced inspiration and expiration, respectively, from statistical analysis.

Lung sounds were recorded using microphones on the right chest wall over the 2nd (Mic1) and 5th (Mic2) intercostal spaces at the mid-clavicular line, and over the 9th intercostal space at the mid-scapular line (Mic3) [3]. The microphones (air-coupled piezoelectric microphones, Sony ECM-150T, Japan; volume of air-coupling $2 \mathrm{ml}$ ) were mounted in metal housings that were attached to the chest wall using double-sided adhesive tape rings. When fixed to the chest wall, the microphones had a measured frequency response from 150 to $3 \mathrm{kHz}( \pm 3$ dB). Microphone signals were amplified and filtered (4th-order Bessel filters: high-pass cut-off at $100 \mathrm{~Hz}$ and low-pass cut-off at $1.5 \mathrm{kHz}$ ). Lung volume, flow rate and lung sounds were digitized at $5 \mathrm{kHz}$ (analog-to-digital convertor: Metrabyte Corp. DASH-16F, USA) and stored on the hard disk of the MS-DOS computer (Mitac AT386DX, Japan).

\section{Signal analysis}

For each recording, lung sound samples were selected for which the corresponding airflow was a multiple integer of $0.1 l \cdot \mathrm{s}^{-1}$ for quiet breathing manoeuvres, and 0.3 $l \cdot \mathrm{s}^{-1}$ for forced manoeuvres. These samples were used as centre points for $100 \mathrm{~ms}$ intervals, from which flowdependent power spectra were computed by fast Fourier transform using a Hanning window [3]. The spectra were averaged between all respirations of one registration for each distinct airflow value, and separately for the ascending and descending flow-limbs [3] (fig. 1).

For each averaged spectrum the following parameters were determined [3]: 1) lung sound intensity (LSI) expressed as log-power of the area under the spectral curve; 2) frequency content in quartile power points, dividing the power spectra into four equal areas (Q25\%, Q50\%, Q75\%) [15]; and 3) the extent of wheezing, defined as the percentage of subjects for which a wheeze can be detected at a particular airflow (W). Peaks in the power spectrum were considered wheezes when being above $150 \mathrm{~Hz}$ and at least three times greater in intensity than the baseline sound signal $[3,16]$. Finally, we determined the fraction of spectra containing a wheeze to the total number of spectra (W\%) [3]. This was done separately for inspiration and expiration, and for the ascending and descending flow-limbs.

\section{Statistical analysis}

The repeatability of lung sound parameters LSI, Q25\%Q75\%, W and W\% between study days 1 and 2 was analysed using the intraclass correlation coefficient [17].

The effects of methacholine, subject group (asthma or control), flow and flow-limb (ascending or descending) on the lung sound parameters were examined using mixed model ANOVA. As the amount of data had to be reduced for computer memory reasons, we used the averaged values of LSI, Q25\%, Q50\%, Q75\%, W and W\% from Day 1 and Day 2 for further analysis. The analysis was performed separately for the three microphones, for both breathing manoeuvres, for inspiration and expiration, and for ascending and descending flow-limbs. LSI, Q25\%-Q75\% and W were selected as dependent variables, whilst airflow and level of induced obstruction (PPGBL, PPG20\%, and PPG40\%) were used as independent variables [3]. The effect of the methacholine challenge was analysed in two ways: 1) in the total group 
Table 1. - Characteristics of the subjects

\begin{tabular}{|c|c|c|c|c|c|c|c|c|c|}
\hline \multirow{2}{*}{$\begin{array}{l}\text { Subject } \\
\text { No. }\end{array}$} & \multirow{2}{*}{$\begin{array}{l}\text { Age } \\
\text { yrs }\end{array}$} & \multirow{2}{*}{$\begin{array}{l}\text { Height } \\
\mathrm{cm}\end{array}$} & \multirow{2}{*}{$\begin{array}{c}\mathrm{PC} 20 \\
\mathrm{mg} \cdot \mathrm{ml}^{-1}\end{array}$} & \multicolumn{2}{|c|}{$\begin{array}{c}\mathrm{FEV}_{1} \text { PPGBL } \\
\% \text { pred }\end{array}$} & \multicolumn{2}{|c|}{$\begin{array}{c}\Delta \mathrm{FEV}_{1} \mathrm{PPG}_{20 \%} \\
\% \text { pred }\end{array}$} & \multicolumn{2}{|c|}{$\begin{array}{c}\Delta \mathrm{FEV}_{1} \mathrm{PPG} 40 \% \\
\% \text { pred }\end{array}$} \\
\hline & & & & Day 1 & Day 2 & Day 1 & Day 2 & Day 1 & Day 2 \\
\hline \multicolumn{10}{|l|}{ Normal } \\
\hline 1 & 24 & 185 & 69.4 & 124 & 126 & 31.9 & 24.0 & - & - \\
\hline 2 & 19 & 180 & 46.4 & 120 & 114 & 23.4 & 21.4 & - & - \\
\hline 3 & 21 & 176 & 120.6 & 115 & 119 & 29.8 & 31.4 & - & - \\
\hline 4 & 21 & 191 & 84.5 & 110 & 112 & 22.8 & 21.4 & - & - \\
\hline 5 & 22 & 179 & 56.2 & 107 & 106 & 34.1 & 33.6 & - & - \\
\hline 6 & 23 & 180 & 45.9 & 105 & 105 & 20.7 & 26.4 & - & - \\
\hline 7 & 22 & 195 & 25.0 & 103 & 103 & 32.5 & 28.1 & - & - \\
\hline 8 & 23 & 195 & 112.7 & 88 & 89 & 26.4 & 25.2 & - & - \\
\hline Mean & 22 & 185 & 70.1 & 109 & 109 & 27.7 & 26.4 & - & - \\
\hline $\mathrm{SD}$ & 1.6 & 7.6 & 33.7 & 11.1 & 11.2 & 5.1 & 4.4 & - & - \\
\hline \multicolumn{10}{|l|}{ Asthma } \\
\hline 9 & 23 & 183 & 2.28 & 119 & 114 & 27.6 & 22.9 & 39.6 & 42.0 \\
\hline 10 & 22 & 178 & 0.61 & 113 & 110 & 24.9 & 29.6 & 52.0 & 51.5 \\
\hline 11 & 19 & 180 & 0.50 & 104 & 101 & 29.1 & 24.9 & 46.9 & 49.4 \\
\hline 12 & 28 & 183 & 1.11 & 96 & 98 & 25.1 & 27.6 & 44.4 & 46.0 \\
\hline 13 & 28 & 184 & 4.02 & 95 & 93 & 24.7 & 25.2 & 45.5 & 40.1 \\
\hline 14 & 22 & 173 & 1.67 & 84 & 84 & 20.7 & 23.9 & 39.4 & 49.9 \\
\hline 15 & 28 & 179 & 0.14 & 81 & 81 & 22.2 & 30.4 & 48.8 & 44.2 \\
\hline 16 & 28 & 170 & 0.35 & 81 & 80 & 26.2 & 21.3 & 43.7 & 40.7 \\
\hline 17 & 23 & 186 & 0.50 & 77 & 78 & 21.4 & 21.8 & 45.5 & 43.4 \\
\hline Mean & 25 & 180 & 1.24 & 94.5 & 93 & 24.7 & 25.3 & 45.1 & 45.2 \\
\hline $\mathrm{SD}$ & 3.5 & 5.3 & 1.25 & 14.9 & 13.5 & 2.8 & 3.3 & 4.0 & 4.2 \\
\hline p-value\# & 0.06 & 0.10 & 0.00 & 0.04 & 0.02 & 0.14 & 0.55 & - & - \\
\hline
\end{tabular}

$\mathrm{FEV}_{1}$ : forced expiratory volume in one second; $\mathrm{PC}_{20}$ : provocative concentration of methacholine producing a $20 \%$ fall in $\mathrm{FEV}_{1}$; PPGBL: baseline phonopneumographic measurement; PPG20\% and PPG40\%: phonopneumographic measurements following a $20 \%$ and $40 \%$ fall in $\mathrm{FEV}_{1}\left(\Delta \mathrm{FEV}_{1}\right)$, respectively; \#: p-value between normal and asthmatic subjects.

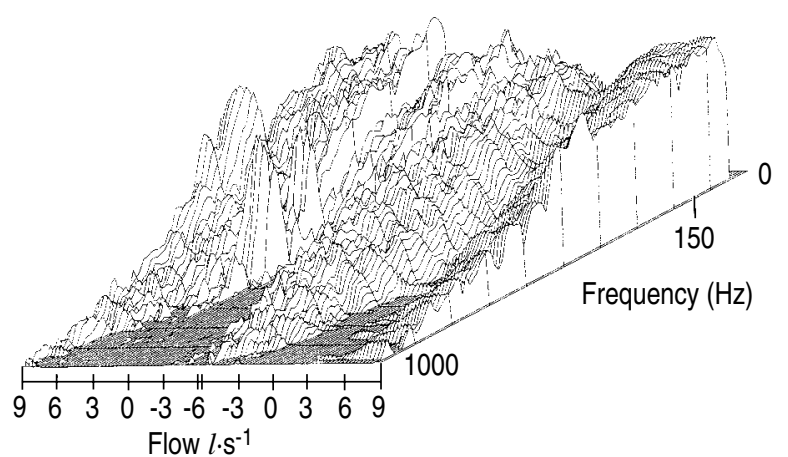

Fig. 1. - Representative pseudo-three-dimensional plot of power spectra after averaging between eight breaths. Wheezes can be distinguished as narrow peaks, in particular at the left side of the figure (expiration, decreasing flow-limb).

of subjects, the dependent variables were compared between two levels of obstruction (PPGBL and PPG20\%), with group (asthma or normal) as independent variable; and 2) in asthmatic subjects only, the dependent variables were compared between three levels of obstruction (PPGBL, PPG20\% and PPG40\%). W\% was analysed similarly, but without taking the effect of airflow into account.

ANOVA was performed between 0.3 and $1.5 l \cdot \mathrm{s}^{-1}$ for quiet breathing manoeuvres, between 0.6 and $3.6 l \cdot \mathrm{s}^{-1}$ for forced inspirations, and between 0.6 and $6.0 l \cdot \mathrm{s}^{-1}$ for forced expirations. $\mathrm{FEV}_{1} \%$ predicted at baseline was applied as a covariate to take into account any differences in $\mathrm{FEV}_{1}$ between subjects. Values of $\mathrm{p}$ less than 0.05 were considered significant.

\section{Results}

\section{Lung function characteristics}

The difference in baseline $\mathrm{FEV}_{1}$ between the study days was $\leq 5 \%$ of the predicted value in each subject. Mean $\mathrm{FEV}_{1}$ at any of phonopneumographic recordings was not significantly different between the study days $(\mathrm{p}=0.30)$. The mean $\mathrm{FEV}_{1}$ at baseline in asthmatic subjects was lower than in healthy controls $(\mathrm{p}=0.04)$ (table 1). The fall from baseline in $\mathrm{FEV}_{1}$ at $\mathrm{PPG}_{20 \%}$, however, was not different between the groups $(p=0.14)$. 
a) Quiet

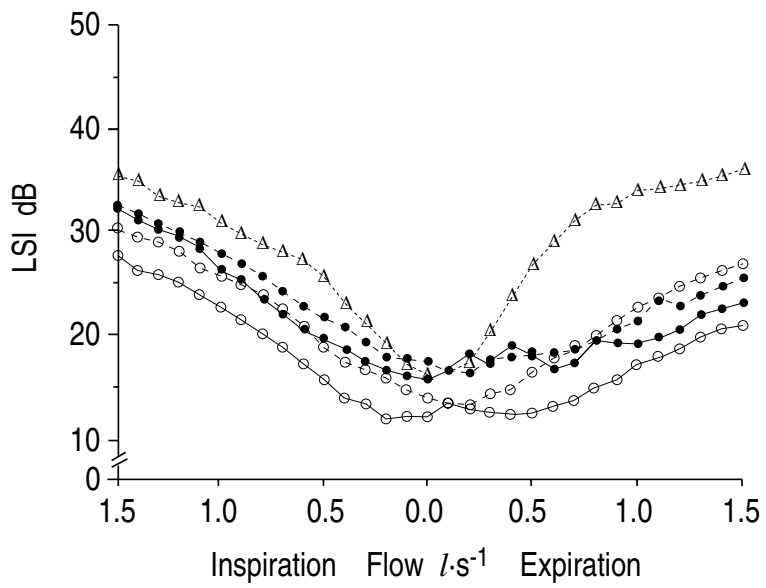

b) Maximum forced

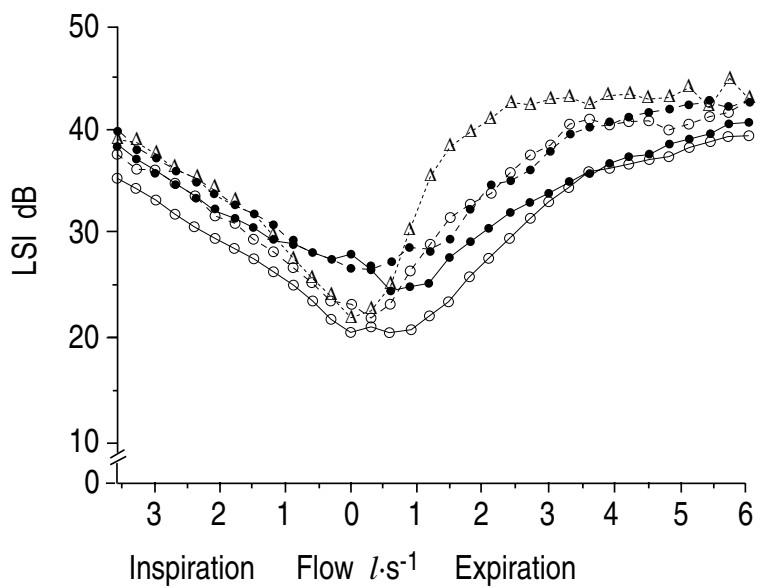

Fig. 2. - Lung sound intensity (LSI) versus airflow recorded by Mic2 during: a) standardized quiet breathing; and b) maximum forced breathing. Inspiration is displayed to the left, expiration to the right. Note that the vertical axis are cut off from zero. At baseline (PPGBL) LSI was lower in asthmatic than in normal subjects during expiration. LSI was louder at PPG20\% and PPG40\% than at baseline during quiet respiration and forced expiration.

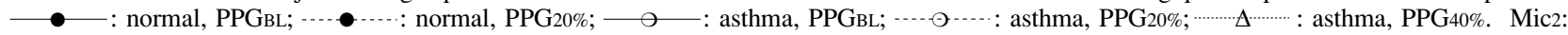
microphone on the right chest wall over the 5th intercostal space at the mid-clavicular line; PPGBL: baseline phonopneumographic measurement; $\mathrm{PPG}_{20 \%}$ and PPG40\%: phonopneumographic measurement following a 20\% and $40 \%$ fall in $\mathrm{FEV}_{1}$, respectively.

a) Quiet

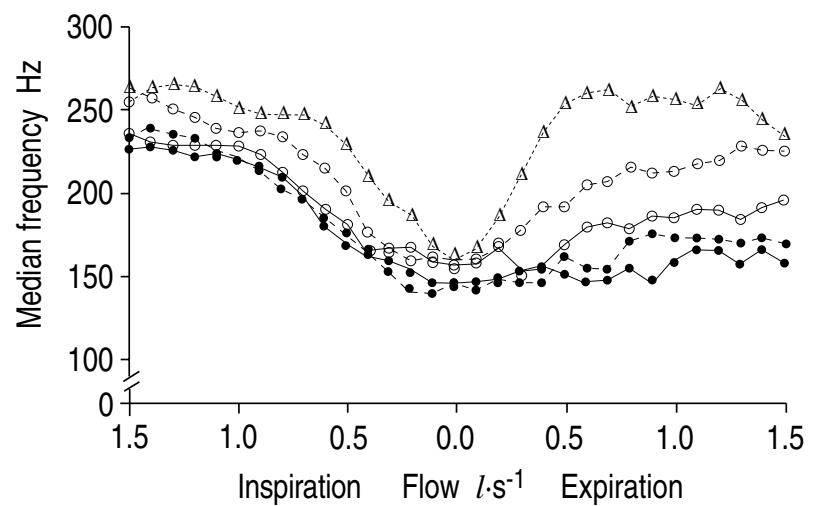

b) Maximum forced

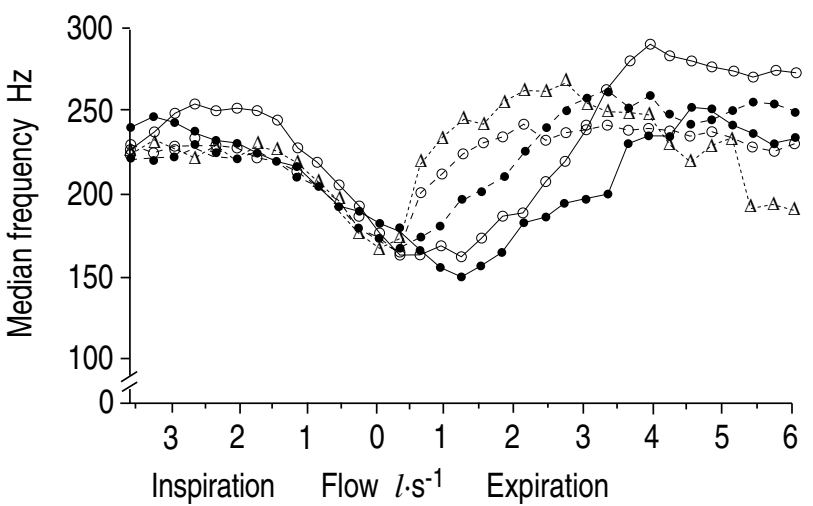

Fig. 3. - Median frequency (Q50\%) versus airflow recorded by Mic2 during: a) standardized quiet breathing; and b) maximum forced breathing. Inspiration is displayed to the left, expiration to the right. Note that the vertical axes are cut off from zero. At baseline (PPGBL) Q50\% was higher in asthmatic than normal subjects for quiet expirations. At PPG20\% and PPG40\% Q50\% was higher than at baseline during quiet expiration. During forced expirations Q50\% was higher at PPGBL and PPG20\% in asthmatic subjects than in healthy controls. ———

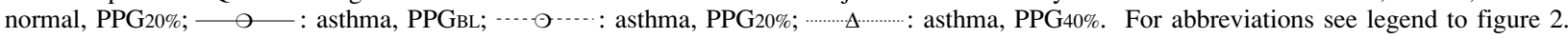

a) Quiet

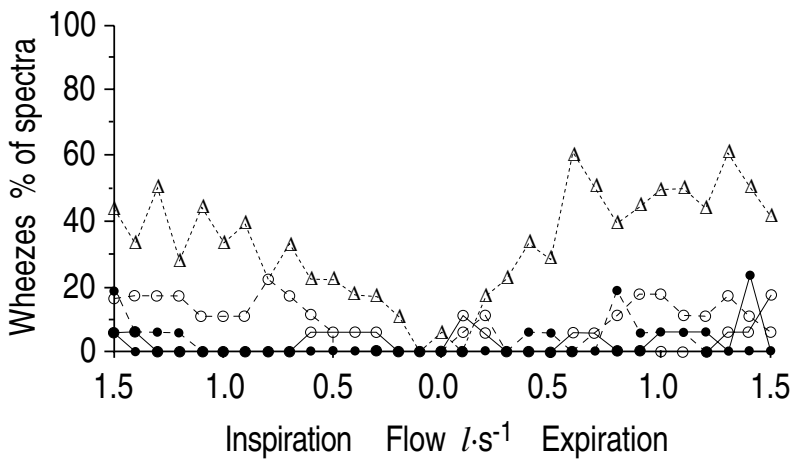

b) Maximum forced

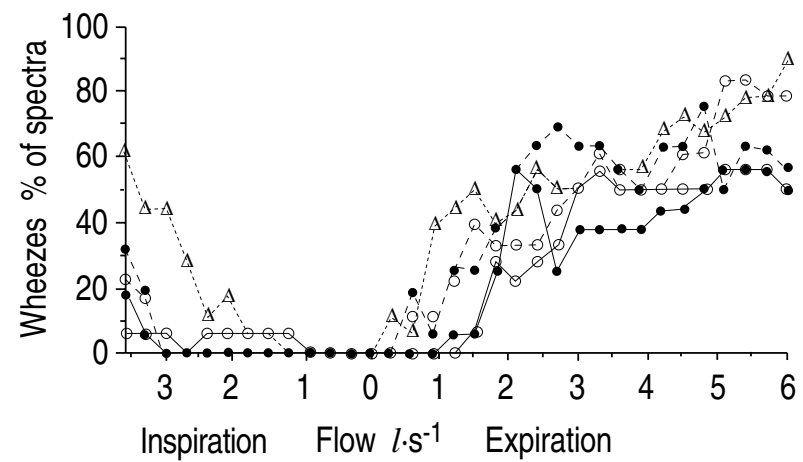

Fig. 4. - Extent of wheezing (W) versus airflow recorded by Mic2 during: a) standardized quiet breathing; and b) maximum forced breathing. Inspiration is displayed to the left, expiration to the right. At baseline (PPGBL) W was not different between normal and asthmatic subjects. At PPG20\% and PPG40\% W was higher than at PPGBL during quiet respiration and during forced expiration. During quiet respiration wheezing was

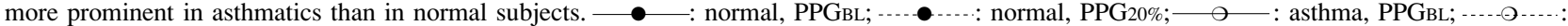
asthma, PPG20\%; ................ : asthma, PPG40\%. For abbreviations see legend to figure 2. 


\section{Lung sound parameters}

Results of lung sound parameters at baseline have been extensively reported elsewhere [3].

LSI. After inhalation of methacholine (PPG20\%) lung sounds were louder than at baseline in both subject groups during quiet respiration $(\mathrm{p}=0.013)$ and during forced expiration $(\mathrm{p}<0.034)$ (fig. 2$)$. Moreover, during quiet breathing at PPG20\% the change in sound intensity with airflow was greater than at baseline $(\mathrm{p}=0.012)$ (fig. 2$)$. Similarly, the increase in intensity with airflow was greater in patients with asthma than in normal subjects during forced expiration $(\mathrm{p} \leq 0.001)$.

During severe airway narrowing (PPG40\%) lung sounds were louder than at PPGBL and at PPG20\% during quiet breathing $(\mathrm{p}=0.029)$ and during forced expiration $(\mathrm{p}=0.002)$ (fig. 2). Furthermore, the change in intensity with airflow was greater during expiration at $\mathrm{PPG} 40 \%$ than at lower levels of obstruction $(\mathrm{p}=0.012)$ (fig. 2).

Q25\%-Q75\%. Quartile power point frequencies Q25\% -Q75\% were higher at PPG20\% than at PPGBL during quiet expiration in both groups $(\mathrm{p}=0.002)$. This was even more evident for PPG40\% in asthmatics $(\mathrm{p}=0.001)$ (fig. 3 ). Furthermore, the change with airflow of Q25\%-Q75\% was greater at $\mathrm{PPG} 20 \%$ than at baseline for quiet expiration ( $p=0.047)$ (fig. 3). At PPGBL and PPG20\% both Q25\% and Q50\% were higher in asthmatic subjects than in healthy controls for Mic2 and Mic3 during quiet expirations $(\mathrm{p}=0.028)$, being also more strongly dependent on airflow $(\mathrm{p}=0.036)$. During forced expirations the increase in Q25\%-Q75\% with airflow was greater in asthmatic subjects than in healthy controls for Mic1 and Mic3 ( $\leq 0.032)$.
$W$ and $W \%$. During forced expiration the extent of wheezing (W) increased progressively from baseline to PPG $20 \%$ in both subject groups ( $\mathrm{p}=0.028$ ), and to PPG $40 \%$ in asthmatics ( $\mathrm{p} \leq 0.001$ ) (fig. 4). During quiet breathing, the extent of wheezing also increased in the decreasing flow-limb from PPGBL to PPG $20 \%$ in both groups $(\mathrm{p} \leq 0.010)$, and to PPG40\% in the asthmatics $(\mathrm{p} \leq 0.001)$. W was greater in asthmatics than in normal subjects $(\mathrm{p} \leq 0.024)$ (fig. 4), whilst the fraction of spectra containing a wheeze to the total number of spectra (W\%) was not different between the subject groups ( $\mathrm{p} \geq 0.09)$, or between PPGBL and $\mathrm{PPG} 20 \%(\mathrm{p}=0.07)$.

\section{Effects of airflow on lung sound parameters}

LSI and Q25\% to Q75\% were strongly dependent on airflow in both types of respiratory manoeuvres during inspiration as well as expiration, and before and after methacholine ( $\mathrm{p} \leq 0.001)$ (figs 2 and 3$)$. $\mathrm{W}$, however, was not dependent on airflow $(\mathrm{p}=0.084)$, except during forced expiration ( $\mathrm{p} \leq 0.001)$ (fig. 4$)$.

\section{Repeatability}

The intraclass correlation coefficient for LSI, Q25\% to $\mathrm{Q} 75 \%$, and wheeze parameters (W and $\mathrm{W} \%$ ) decreased with increasing levels of obstruction (PPG20\% and PPG40\%) as compared with baseline (PPGBL) (table 2). Wheezing at baseline and PPG20\% occurred to a considerable extent during forced expiration only. As wheezing was rare during quiet and forced inspiration and during quiet expiration, calculation of the intraclass correlation coefficient for $\mathrm{W}$ and $\mathrm{W} \%$ in these segments of the recordings

Table 2. - Intraclass correlation coefficients of the results of study days 1 and 2 for asthmatic and normal subjects for PPGBL, PPG20\% and PPG40\%

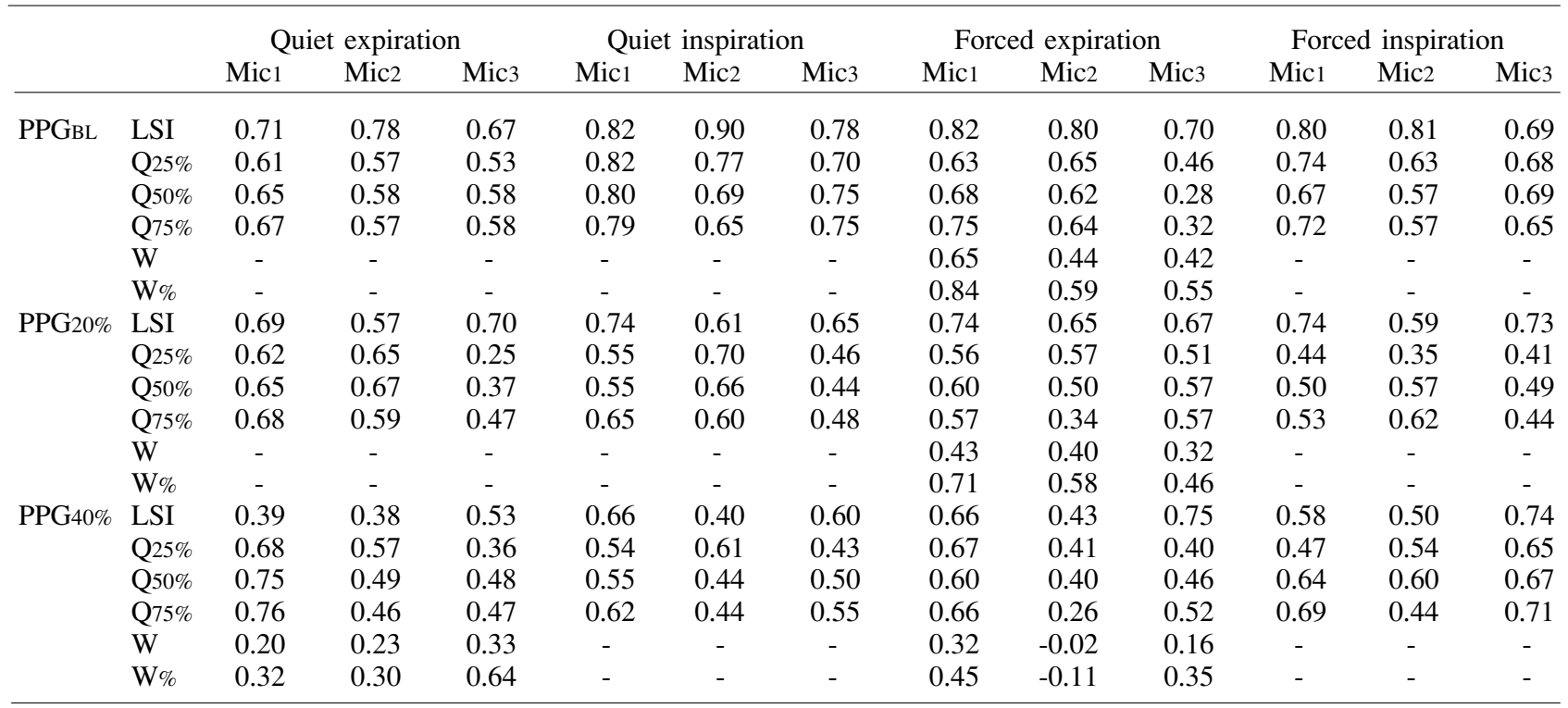

LSI: lung sound intensity; Q25\%-Q75\%: frequency content in quartile power points; W: percentage of subjects for which a wheeze can be detected at a particular airflow; W\%: fraction of spectra containing a wheeze to the total number of spectra; Mic1 and Mic2: microphones on the right chest wall over the 2nd and 5th intercostal spaces, respectively, at the mid-clavicular line; Mic3: microphone over the 9 th intercostal space at the mid-scapular line. For further abbreviations see legend to table 1. 
was not meaningful. Due to the large variation of $\mathrm{W}$ and $\mathrm{W} \%$ between the study days at PPG $40 \%$, the accompanying intraclass correlation coefficient values were low (table 2). Therefore, $\mathrm{W}$ and $\mathrm{W} \%$ at PPG40\% were excluded from further analysis.

\section{Discussion}

The present findings demonstrate that the intensity and pitch of lung sounds, as well as the extent of wheezing, all increase during acute airway narrowing in normal and asthmatic subjects. At similar levels of induced obstruction, both the pitch and the rate of change in sound intensity with airflow, appear to be higher in asthmatics as compared with normal subjects. In addition, wheezing, not being discriminative between these groups at baseline conditions [3], is more prominent in asthmatic than in normal subjects during methacholine challenge. These findings suggest that the generation and/or transmission of lung sounds during acute airway narrowing are modified by morphological abnormalities of the airway wall in patients with asthma.

This is the first study in which lung sound characteristics have been examined during acutely induced airways obstruction using airflow- and volume-standardized phonopneumography and flow-dependent lung sound analysis. The results are in agreement with earlier studies in which intensity [18, 19], pitch [18-21], and wheezing in children [22-24] and adults [20, 25, 26] were increased during spontaneous or induced airways obstruction. In contrast, BOHADANA and co-workers [27, 28] found that lung sound intensity was reduced during bronchoconstriction, probably due to a change in breathing pattern. Based on the standardized breathing manoeuvres, this could be avoided in the present experiments. Breathing pattern had not been fully standardized in any of the previous studies, the analysis being based on subjective auscultation [26, 27], or on computerized analysis [18-25, 28], without discrimination of discrete flow-values or ascending and descending flow. Therefore, the results of the present study indicate that changes in lung sounds during acute airway narrowing do not only result from alterations in breathing pattern.

Lung sounds showed many similarities between normal and asthmatic subjects before and during acute airway narrowing. Intensity, frequency content, and wheezing were dependent on airflow, which is in agreement with earlier studies $[3,6,24,29,30]$. The discrepancies in the results of ascending and descending flow-limbs confirm our findings at baseline [3], and suggest that lung sound generation and/or transmission vary during the respiratory cycle. We speculate that this results from differences in lung volume at similar airflows between ascending and descending flow. It implies that lung sound analysis may be obscured, when airflow or lung volume are not taken into consideration.

The reproducibility of lung sound intensity and frequency content between the study days decreased with the level of obstruction, even though the changes in $\mathrm{FEV}_{1}$ were stable between the two days. This might have resulted from the increase in the extent of wheezing during obstruction. The reproducibility of wheezing has been reported to be relatively unsatisfactory $[3,20]$, and this will have influenced both the intensity and frequency content of lung sounds. The variability of wheezing during airway narrowing is certainly due to the variable presence and changing sites of airflow limitation undetected by $\mathrm{FEV}_{1}$ [5], and is, therefore, an inherent characteristic of this parameter.

The present results may have been influenced by methodological factors. Firstly, in contrast to normal subjects, patients with asthma may produce airway secretions, which create local conditions favouring the production of wheezes. Although the high doses of methacholine that were used in normal subjects to obtain the required fall in $\mathrm{FEV}_{1}$ at $\mathrm{PPG} 20 \%$ would also enhance mucus production [31], it cannot be excluded that these secretions affected the results of this study.

Secondly, the wheeze detection algorithm may have influenced the results of this study. Wheezes can be recognized as sharp peaks in power spectra [32,33]. During severe airways obstruction polyphonic wheezing will occur [33]. The resulting multitude of spectral peaks was not always detectable due to partial confluence of individual peaks, thus leading to underestimation of the extent of wheezing. This might, in part, explain the relatively low reproducibility of wheeze parameters at PPG40\%. However, careful listening enabled us to exclude the presence of significant polyphonic wheezing at PPGBL and PPG20\%. As the analysis of wheeze parameters at PPG40\% was omitted, we considered the currently applied method for wheeze detection adequate.

How can we explain the effects of methacholine on lung sound characteristics? Methacholine induces narrowing of the airway lumina by smooth muscle contraction [31]. The resulting increase in local airflow velocity at given flows at the mouth will enhance turbulence, thus, generating more powerful sound pressure waves with a higher frequency content [4]. A given fall in lung function in normal and asthmatic subjects is likely to be due to a similar reduction of intraluminal airway diameters, and is likely to result in similar increases in local airflow velocities and turbulence. However, as baseline $\mathrm{FEV}_{1}$ was lower in asthmatics than in controls, airflow velocities will have been relatively higher in the asthmatics, even after a similar fall in $\mathrm{FEV}_{1}$ in both subject groups. As the power of normal lung sounds is proportional to the square of airflow velocity $[6,29]$, intensity and frequency content in asthmatics will have increased more rapidly with increasing airflow and increasing obstruction [4]. This is in agreement with our findings that the increase in intensity and pitch with airflow and with the level of obstruction was higher in the asthmatic than in the normal subjects.

It is unlikely that sound transmission from the airway lumen to the chest wall was seriously changed during methacholine challenge in our experiments. Sound transmission primarily depends on parenchymal density and stiffness, and the sound energy transmitted across boundaries between tissue types [7]. Airway narrowing increases airway wall thickness [8, 9], and possibly 
decreases parenchymal density $[10,11]$. Both these factors may reduce sound transmission [7]. However, lung sound intensity increased with the level of obstruction, particularly in asthmatics in whom the airway wall swelling is likely to be more prominent than in normal subjects $[8,9]$. This indicates that the transmission of lung sounds is relatively unaffected during methacholine challenge, and that increased sound production predominates under these conditions.

The extent of wheezing increased with the level of obstruction, the more so in asthmatics as compared with normal subjects. This is likely to be due to flow-limitation occurring at lower airflow velocities when airway diameter is decreased [5]. The increase in local airflow velocity during obstruction facilitates critical airflow velocity to be reached, and thereby flow limitation and wheezing to take place at relatively low airflows at the mouth. Again, it is likely that the morphological changes in asthma, such as increased airway wall thickness and reduced intraluminal diameters, enhance flow limitation. Therefore, our observations suggest that the swollen airway walls in asthmatics have increased the extent of wheezing as compared with normal subjects, even though the relative change in $\mathrm{FEV}_{1}$ was similar in both groups of subjects.

What are the clinical implications of this study? Firstly, the most prominent differences in sound intensity and frequency content between the asthmatics and normal subjects were found during standardized quiet breathing. This finding, together with the airflow-dependence of the lung sound parameters, indicates the importance of using quiet, well-controlled flow-volume manoeuvres during auscultation. Secondly, the relatively high variability of wheezing during obstruction indicates that, even during flow-volume standardized manoeuvres within one individual subject, similar levels of obstruction do not necessarily lead to similar lung sounds. Thus, wheezing as a measure for airways obstruction should be used with caution. And finally, it needs to be emphasized that methacholine-induced obstruction is artificially causing smooth muscle contraction. Variable airways obstruction due to naturally occurring stimuli, such as allergens or exercise, are likely to be mediated by inflammatory mechanisms. The effect of such stimuli on lung sounds might be different from those obtained by methacholine, and require further investigation.

We conclude that the intensity and pitch of lung sounds, as well as the extent of wheezing, increase during acute airway narrowing both in normal and asthmatic subjects. The changes in these lung sound characteristics at given degrees of bronchoconstriction differ between these groups of subjects, which is likely to result from morphological abnormalities of the airways in asthma. Our results indicate the importance of airflow- and lung volumestandardized phonopneumography in lung sound research, and strongly suggest the relevance of well-controlled breathing manoeuvres during clinical auscultation.

Acknowledgements: The authors thank M. Timmers for carrying out the lung function tests of the subjects, and R. Schot and R. Klein for technical assistance.

\section{References}

1. Djukanovic R, Roche WR, Wilson JW, et al. State of the art: mucosal inflammation in asthma. Am Rev Respir Dis 1990; 142: 434-457.

2. Beasley R, Roche WR, Roberts JA, Holgate ST. Cellular events in the bronchi in mild asthma and after bronchial provocation. Am Rev Respir Dis 1989; 139: 806-817.

3. Schreur HJW, Vanderschoot J, Zwinderman AH, Dijkman JH, Sterk PJ. Abnormal lung sounds in patients with asthma during episodes with normal lung function. Chest 1994; 106: 91-99.

4. Olson DE, Hammersley JR. Mechanisms of lung sound generation. Semin Respir Med 1985; 6: 171-179.

5. Grotberg JB, Gavriely N. Flutter in collapsible tubes: a theoretical model of wheezes. J Appl Physiol 1989; 66: 2262-2273.

6. Kraman SS, Wang PM. Airflow-generated sound in a hollow canine airway cast. Chest 1990; 97: 461-466.

7. Rice DA. Sound speed in pulmonary parenchyma. $J$ Appl Physiol: Respirat Environ Exercise Physiol 1983; 54: 304-308.

8. Moreno RH, Hogg JC, Paré PD. Mechanics of airway narrowing. Am Rev Respir Dis 1986; 133: 1171-1180.

9. James AL, Paré PD, Hogg JC. The mechanics of airway narrowing in asthma. Am Rev Respir Dis 1989; 139: 242-246.

10. Nagase T, Lei M, Robatto FM, Eidelman DH, Ludwig MS. Tissue viscance during induced constriction in rabbit lungs: morphological-physiological correlations. $J$ Appl Physiol 1992; 73: 1900-1907.

11. Eidelman DH, Lei M, Ghezzo RH. Morphometry of methacholine-induced bronchoconstriction in the rat. $J$ Appl Physiol 1993; 75: 1702-1710.

12. Quanjer PhH, Tammeling GJ, Cotes JE, Pedersen OF, Peslin R, Yernault J-C. Lung volumes and forced ventilatory flows. Eur Respir J 1993; 6 (Suppl. 16): $5-40$.

13. Sterk PJ, Fabbri LM, Quanjer PhH, et al. Airway responsiveness: standardized challenge testing with pharmacological, physical and sensitizing stimuli in adults. Eur Respir J 1993; 6 (Suppl. 16): 53-83.

14. Fish JE, Ankin MG, Kelly JF, Peterman VI. Regulation of bronchomotor tone by lung inflation in asthmatic and nonasthmatic subjects. J Appl Physiol: Respirat Environ Exercise Physiol 1981; 50: 1079-1086.

15. Kraman SS. The forced expiratory wheeze: its site of origin and possible association with lung compliance. Respiration 1983; 44: 189-196.

16. Baughman RP, Loudon RG. Stridor: differentiation from asthma or upper airway noise. Am Rev Respir Dis 1989; 139: 1407-1409.

17. Snedecor GW, Cochran WG. In: Statistical methods. 7th edn. Ames, lowa, State University Press, 1980; pp. 282-285.

18. Malmberg LP, Sovijärvi ARA, Paajanen E, Piirilä P, Haahtela T, Katila T. Changes in frequency spectra of breath sounds during histamine challenge test in adult asthmatics and healthy control subjects. Chest 1994; 105: 122-132.

19. Tinkelman DG, Lutz C, Conner B. Methacholine challenges in the management of young children. Ann Allergy 1991; 66: 225-230.

20. Spence DPS, Bently S, Evans DH, Morgan MDL. Effect of methacholine-induced bronchoconstriction on the spectral characteristics of breath sounds in asthma. Thorax 1992; 47: 680-683. 
21. Anderson K, Aitken S, Carter R, MacLeod JES, Moran F. Variation of breath sound and airway caliber induced by histamine challenge. Am Rev Respir Dis 1990; 141: 1147-1150.

22. Beck R, Dickson U, Montgomery MD, Mitchell I. Histamine challenge in young children using computerized lung sounds analysis. Chest 1992; 102: 759-763.

23. Sanchez I, Avital A, Wong I, Tal A, Pasterkamp H. Acoustic vs spirometric assessment of bronchial responsiveness to methacholine in children. Pediatr Pulmonol 1993; 15: 28-35.

24. Fenton TR, Pasterkamp H, Chernick V. Automated spectral characterization of wheezing in asthmatic children. IEEE Trans Biomed Eng 1985; BME-32: 50-55.

25. Baughman RP, Loudon RG. Lung sound analysis for continuous evaluation of airflow obstruction in asthma. Chest 1985; 88: 364-368.

26. Shim CS, Williams MH. Relationship of wheezing to the severity of obstruction in asthma. Arch Intern Med 1983; 143: 890-892.

27. Bohadana $A B$, Peslin R, Uffholtz H. Breath sounds in the clinical assessment of airflow obstruction. Thorax 1978; 33: 345-351.

28. Bohadana AB, Kopferschmitt-Kubler MC, Pauli G. Vesicular sound intensity (VSI) during airway provocation challenge. Eur Respir J 1993; 6: 600s.

29. Shykoff BE, Ploysongsang Y, Chang HK. Airflow and normal lung sounds. Am Rev Respir Dis 1988; 137: 872-876.

30. Lessard CS, Wong WC. Correlation of constant flow rate with frequency spectrum of respiratory sounds when measured at the trachea. IEEE Trans Biomed Eng 1986; BME-33: 461-463.

31. Barnes PJ. Muscarinic receptor subtypes. Eur Respir J 1993; 6: 328-331.

32. Loudon RG, Murphy RLH. Lung sounds. In: Crystal RG, West JB, Barnes PJ, Cherniack NS, Weibel ER, eds. The Lung. New York, Raven Press Ltd, 1991; pp. 10111019.

33. Waring WW, Beckerman RC, Hopkins RL. Continuous adventitious lung sounds: site and method of production and significance. Semin Respir Med 1985; 6: 201-209. 